\title{
The Pursuit of Social Justice in Kavery Nambisan's The Hills of Angheri
}

\section{OPEN ACCESS}

Manuscript ID:

ENG-2020-08033180

Volume: 8

Issue: 3

Month: June

Year: 2020

P-ISSN: 2320-2645

E-ISSN: 2582-3531

Received: 28.04 .2020

Accepted: 20.05.2020

Published: 02.06.2020

Citation:

Daya Bhagya Sherin, M. "The Pursuit of Social Justice in Kavery Nambisan's The Hills of Angheri." Shanlax International Journal of English, vol. 8, no. 3, 2020, pp. 49-53.

DOI:

https://doi.org/10.34293/ english.v8i3.3180

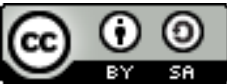

This work is licensed under a Creative Commons AttributionShareAlike 4.0 International License

\author{
M. Daya Bhagya Sherin \\ Ph.D. Research Scholar, Department of English \\ CTTE College for Women, Chennai, Tamil Nadu, India \\ (D) https://orcid.org/0000-0003-2262-1732
}

\begin{abstract}
This paper critically examines Kavery Nambisan's novel The Hills of Angheri under the lens of Dr. Amartya Sen's Capability Approach. The core concepts of this approach serve as critical tools in assessing the social inequities existing in Indian society. Kavery speaks about the massive inadequacy of healthcare and basic amenities found in rural places, especially in the village Angheri. Both Sen and Kavery aspire for the enhancement of a person's well-being. They truly believe that necessities such as education, health are requisite for an individual to achieve more in life. The unfavorable socio-economic conditions and the unavailability of the basic medical care within his reach create social insecurity. Kavery brings to light the dearth of hospitals in our rural villages and reinforces the need for well-equipped hospitals and highly qualified doctors in the village. She expresses her anguish that most of the doctors flock to cities and neglect the villages where seventy or seventy-five percent of the people live. She points out the need for facilitating health care amenities in the health-care deprived villages to ensure social justice in the society. The novelist wants better health-care conditions to be made accessible to all, irrespective of their socio-economic status. The health disparities in villages can be eliminated if socially-responsible persons like the protagonist Nalli volunteer to serve the less advantaged people.
\end{abstract}

Keywords: Capability approach, Health equity, Well-being, Capability, Functionings, Agency, Agency freedom, and Achievement.

\section{Introduction}

The capability approach is a theoretical framework pioneered by EconomistPhilosopher Dr. Amartya Sen to evaluate individual well-being. This approach aims at expanding the opportunities or capabilities of the people to improve their state of well-being. A person's achievements or 'functionings' must be taken into consideration for his well-being assessment. The functionings constitute of 'beings' and 'doings' that include 'elementary things as being adequately nourished, being in good health, avoiding escapable morbidity and premature mortality, etc., to more complex achievements such as being happy, having self-respect, taking part in the life of the community, and so on (Sen 1995: 39). Capability refers to a person's freedom or opportunity to achieve these valuable functionings. The 'capabilities' termed as 'wellbeing freedoms' enable a person to accomplish 'well-being achievements' or 'functionings.' The lack or the absence of well-being or substantive freedoms such as elementary education, basic health care, socio-economic facilities, hygienic surrounding, safe shelter, pure water are considered as deprivations or 'unfreedom.'

The capability approach focuses on the removal of such deprivations and the expansion of these basic freedoms or capabilities to lead the kind of lives they value and have reasons to value. The capabilities are considered as basic building blocks and also the principal determinant of individual initiatives, and they enhance the ability of a person to help themselves and influence the world (18). This is referred to as the 'agency aspect' of an individual. 
The 'agent' acts and brings about social changes. The agents making the fullest use of their agency freedom bring about achievements they value, other than their well-being goals. These goals can be addressed as 'agency achievements' or non-well being goals. Agency encompasses all the goals that a person has reasons to adopt, which can, among other things, include goals other than the advancement of his or her well-being. (Sen 2009: 287). Freedom and agency are mutually enhancing components of development. The endowments include the resources available to the individuals that include biological, mental, private means (income, wealth, physical assets) and intangible resources such as political practices and social institutions, cultural practices, social norms and values, traditions, and habits. The conversion factors reflect people's different personal, social, and environmental characteristics that affect either in a positive or a negative sense. These factors help the individuals to convert their endowments and external conditions into effective capabilities (Chiappero 2014:711).

This paper interprets the novel The Hills of Angheri using the framework of the capability approach. Nalinakshi, a rural-bred girl from a traditional society of Angheri wishes to pursue her dream of becoming a doctor and of establishing a hospital at her village, with the support of her childhood friend Jayanth. Despite the objections raised by her family and the villagers, Nalli alias Nalinakshi adamantly strives to make her dream a reality. After emerging as a qualified surgeon, completing her MBBS in Madras and FRCS in London, she returns to Angheri to start a hospital. Still, to her dismay, she is denied help and support by Jayanth, now a renowned surgeon in Bombay. Nalli is caught between her inner impulse to help the people of her village and her future career prospects. Disillusioned of her dreams, she sets off to Keshvanj to serve in an Ashram's hospital to find solace. Later Nalli moves to Madras to work in a private hospital but fails to attain a sense of satisfaction. At last, she decides to go back to her village Angheri to accomplish 'her childhood dream' of constructing a hospital. Nalli decides to serve the villagers with her acquired knowledge and experience, without expecting any moral support or encouragement from her family, friends, and villagers.
Sen says that 'health is among the important conditions of human life and a critically significant constituent of human capabilities which we have reason to value' (2002:660). Kavery wants health to be granted as freedom or capability to all people irrespective of their socio, economic status because she feels that capabilities of health, education, and equality are interlinked, and they are pre-requisite for any development in a person's life. Sridhar Venkatapuram, a Wellcome Trust Research Fellow (ethics) at the London School of Hygiene and Tropical Medicine in his article "Health, Vital Goals, and Central Human Capabilities" states that the concept of health is not only about the presence or absence of diseases, but about how people feel and what they can do. He feels that the concept of health denotes 'the ability of a person to achieve or exercise a cluster of basic human activities.'

Health is considered as a valuable capability from the point of justice as it helps people to access other valuable goals and capabilities (Nielson 2015: 413). The novelist believes that an individual can achieve more by being in optimal health. Kavery also wishes the people of Angheri to gain this capability to achieve more functionings in life.

Angheri, the village, is twenty miles away from Mysore. There are no colleges, hospitals, or shops in the villages. The existing unfavorable social conditions of the village or the 'unfreedoms' of not having good schools, hospitals, and other employment opportunities (Sen 1999: 15) can be viewed as social injustice. Kavery voices against social injustices such as non-availability of resources, lack of specialized hospitals, and constrained social arrangements in the village that hinders the people from leading a safe and secure life. The people have to travel twenty miles by bullock carts, tractors, or bicycles to get advanced treatments for chronic and contagious ailments (HOA: 35). 'We still have malaria, typhoid, tuberculosis, and infant diarrhea. They can be wiped out if clean water and hygiene are taken care of' (HOA: 344). Kavery portrays Nalli, as a young woman with an aspiration to reform the social inequalities found in the health sphere of her village. Nalli, who has been witnessing unfortunate deaths in her village since childhood, figures out the causation of the problem - the gross deprivation of health care facilities in her village. Nalli being aware 
of the existing social environment, aspires to change the harsh realities of the village. The miserable social situations propel Nalli to facilitate better medical amenities in her health-care deprived village.

Nalli, the protagonist, wishes the villagers to enjoy longevity along with the possible awareness of health and hygiene. The villagers live in substandard conditions and continue to remain ignorant about the health-related issues and their deprivation in their health space. Health care is denied to them for the only reason of living away from a city. They enjoy pure air, uncontaminated water, and good food, but the health care facilities are inaccessible to them. All other freedoms and capabilities that we can exercise are dependent on our health achievements. An individual will not be able to achieve much if she or he is continually bothered by illness (Sen 2002: 663).

Having been born in an upper middle- class family, Nalli enjoys the basic freedoms or capabilities of getting educated, sheltered in a peaceful environment with optimal mental well-being, and physical health to some extent. The freedom and encouragement she receives from her family enabled her to move further towards enhancing her well-being achievements. The positive social conditions influence Nalli to achieve and attain simple and complex functionings. Her simple functionings may include the successful completion of her school education, exposure to a peaceful atmosphere at home, healthy food, and shelter that she receives in good measure. The higher education in England, the experiences as a surgeon in Keshavganj, and in Madras, the exposure to various medical training and trials of the medical life can be valued as her complex functionings. Her determination, hard work, perseverance, and self-will serve as personal endowments and the social circumstances and father's motivation act as the conversion factors helping her to convert the opportunities (capabilities) into functionings. The opportunity or freedom brings transformation in her life. The rural-bred girl achieves her well-being goal or functioning of becoming a highly trained surgeon. Nalli, as an active agent, now wishes to bring social change in her society. Nalli's overall agency goal is to develop the well-being of the villages by removing the health-related deprivation. She accomplishes her non-wellbeing goals by expanding the basic freedom of getting better health care facilities within their proximity. Nalli, as a doctor, brings enhancement in the lives of her people. She decides to utilize the available resources or her skills to make her dream a reality.

Sen states in The Idea of Justice that only a good medical practitioner would understand the two outlooks of health. He terms the two views as 'internal' views based on the patient's perception and the 'external' views based on the trained doctor's observations (284). Kavery, being a medical practitioner, delineates the character of Nalli as a person with the 'internal' outlook of a patient and 'external' outlook of an experienced doctor. Instead of taking 'a distanced and less sensitive view of illness and health,' Kavery takes a humanistic approach to this issue (Sen 2009: 285). Nalli notices the unfairness and injustice in the health-care deprived villages. Investigations and observations need rich discernment and an adequate understanding of the problem (Sen 2009:285). Nalli thinks of improving the health care facilities of her village from a patient's as well as a doctor's point of view.

Fabianne Peter in her article "Health Equity and Social Justice" advocates the need of not only 'a medical model' but also 'a social model' to understand the socio-economic factors 'which play a part in the promotion of health and the causation of disease and in part to take the natural next step and relate these factors themselves to the broader social structure' (161). Kavery has done justice by discussing the three different perceptions of Nalli as a patient, a doctor, and a socially responsible citizen. The novelist has exposed health care problems, along with other social problems. Kavery doesn't isolate health from other socio-economic problems because the need for health care is related to social justice. 'Poovi's five-year-old son dies due to the improper diet given during dysentery. If only Angheri has had a multi-specialty hospital, and the illness could have been treated at the right time, and this premature death could have been averted' (HOA: 135).

Nalli's initial goal is towards the pursuit of her well-being. Nalli materializes her goals into achievements by establishing herself as a successful 
surgeon. Nalli's determination, hard work, and commitment are signs of her desire to improve her well-being objectives. But the readers can sense the agency aspect hidden in her pursuit of attaining more knowledge. If she had not acted as an effective agent in promoting her goals towards the actual realization of becoming a doctor, she could not have dreamt of bringing changes in her village. Sen calls this as 'agency success' (1995:58). Nalli plays an important role in bringing her objectives to realization. The well-being freedom helps her to bring enhancement in others' lives and also to assert agency success. Nalli equips herself with sufficient knowledge and skills to stabilize financially and professionally. This well-being aspect helps her to attain social, economic security, which in turn helps her to fulfill her agency objectives of establishing a hospital for her people. The well-being achievement matures into agency achievement with the ultimate goal of improving the lives of her kinsmen.

No one would be ready to invest their time and money in building a multi-specialty hospital in a village (HOA: 282). But Nalli decides to invest her time and her career in a medical facilities-deprived village. Nalli decides to sacrifice her own-being for the sake of improving the living standards of rural people. The priority she gives for her agencyfreedom and achievement hinders her well-being achievement. She chooses to work in a rural area like Keshvanj. Her well-being achievement is less, but agency success is greater. Nalli could have married and settled in life with better prospects, but she decides to sacrifice her well-being objectives for her agency objectives.

Kavery believes that good health, education has to be offered to the people to earn and live better (HOA: 283). Nalli wishes to rearrange the existing social setup to bring constructive benefits to her people. Nalli wishes to promote health capability to everyone by making better health care accessible. Kavery wants all people irrespective of social, economic status to have their rights to enjoy better health care and to the capability to achieve good health as their functioning. Jenniffer Prah Ruger, Professor of Medical Ethics, the University of Pennsylvania in her article 'Health and Social Justice', states that health is an important aspect of human flourishing because without being alive, no other human functionings can be possible.

Both Kavery and Sen believe that people value education, health, and social equality more than wealth, which relates to the real opportunities to lead the kind of life they would value living (Dreze 2002:34, 35). This expansion of real freedoms (by eliminating illiteracy, ill-health, and social insecurity) can be seen as the central feature of development. Kavery's main message is everyone, by being socially responsible, could bring social justice to people. Kavery wants more 'public-spirited and socially dedicated doctors' (Dreze 2002:204 ) like Nalli to be instrumental in bringing social equality and justice in the health sphere. The health disparities found in villages can be rectified if people like Nalli volunteers to serve people.

\section{Abbreviations \\ HOA - The Hills of Angheri}

\section{Primary Source}

Nambisan, Kavery. The Hills of Angheri. Penguin Books, 2005.

\section{References}

Dreze, Jean and Amartya Sen. India Development and Participation, Oxford University Press, 2002.

Martinetti, Enrica Chiappero and Sridhar Venkatapuram. "The Capability Approach: A Framework for Population Studies." African Population Studies, vol. 28, no. 2, 2014, pp. 708-720.

Nielsen, Lasse. "Why Health Matters to Justice: A Capability Theory Perspective." Ethical Theory and Moral Practice, vol. 18, no. 2, 2015, pp. 403-415.

Peter, Fabianne. "Health Equity and Social Justice". Journal of Applied Philosophy, vol. 18, no. 2, 2001, pp 159-170.

Prah Ruger, Jennifer. "Health and Social Justice." The Lancet, vol. 364, no. 9439, 2004, pp. 1075-1080.

Sen, Amartya K. Development as Freedom, Oxford University Press, New York, 1999. 
Sen, Amartya K. Inequality Reexamined. Oxford Sen, Amartya K. "Why Health Equity?." Health University Press, $1992 . \quad$ Economics, vol. 11, no. 8, 2002, pp. 659-666.

Sen, Amartya K. The Idea of Justice. Penguin Books, Venkatapuram, Sridhar. "Health,Vital Goals and 2009. Central Human Capabilities." Bioethics, vol. 27, no. 5, 2013, pp 271-279.

\section{Author Details}

M. Daya Bhagya Sherin, Ph.D. Research Scholar, Department of English, CTTE College for Women, Chennai, Tamil Nadu, India, Email ID: sherin_muller@rediffmail.com. 